\title{
SOFTWARE COMPLEXITY TOPICS THROUGH THE LENS OF DESIGN PATTERNS
}

\author{
Sabina-Cristiana NECULA \\ Alexandru Ioan Cuza University of Iasi, Romania \\ sabina.necula@uaic.ro \\ Cătălin STRÎMBEI \\ Alexandru Ioan Cuza University of Iasi, Romania \\ linus@uaic.ro
}

\begin{abstract}
The scientific literature has paid limited attention to design patterns for software complexity. This paper compares design patterns and software complexity in order to identify trends of research. For this purpose, we assess the strengths and weaknesses of software complexity scientific articles through the lens of design patterns. We have reviewed 1068 papers via latent dirichlet allocation technique (LDA) for our work. We found that existing software complexity paths disproportionate emphasis in how software complexity can benefit design patterns instead on how contributions to design patterns can benefit software complexity.
\end{abstract}

Keywords: latent dirichlet allocation, design patterns, software complexity, topics.

JEL classification: C45, C55, C83

DOI: $10.12948 / \mathrm{ie} 2019.01 .05$

\section{Introduction}

Various topics on object oriented design have been proposed over the years. Design patterns are a subject of interest because they offer solutions for the coupling and cohesion between different layers of an application. The problems because of a design with high coupling are: changes in related classes force local changes; harder to understand in isolation; harder to reuse because it requires additional presence of other classes. The problems due to a design with low cohesion are: hard to understand; hard to reuse or to maintain. High cohesion means that a class has moderate responsibility in one functional area and it collaborates with other classes to fulfill a task. Software complexity can be reduced by designing systems with the weakest possible coupling between modules [1].

Historically, complexity in programs arising due to the number of conditional and iterative statements has been measured using the cyclomatic complexity metric [2]. Refactoring code with design patterns reduces complexity, although it increases the number of classes. [3]. Khomh and Gueheneuce (2008) [3] show that design patterns do not always improve the quality of systems. Some patterns are reported to decrease some quality attributes and to not necessarily promote reusability, expandability, and understandability. The authors bring further evidence that design patterns should be used with caution during development because they may actually impede maintenance and evolution. This study also reveals that object-oriented principles may not be so "good" as they may not necessarily result in systems with good quality.

However, this subject of studying the effect that source code changes might have on software complexity is not very well represented. The scope of this paper is to identify the main topics, the trends, and to test if there is a correlation between the two subjects. 
www.conferenceie.ase.ro

\section{Methodology}

In this section, we present the research goals and questions to be answered, we describe the inclusion or selection criteria for the studies chosen to analyse, data collection.

The purpose of this article is to get a broad and current overview of the two subjects considered in this paper: design patterns and software complexity. The analysis was realized on academic journal articles. The search for papers was conducted in March 2019 on Thomson Reuters' Web of Science, which has a large interdisciplinary database of academic texts, and limited to peer reviewed articles and reviews in English.

We realized two searches in the title, abstract, and keywords of papers from ISI Clarivate:

- $\quad$ design patterns, which returned 2045 articles;

- "software complexity", which returned 302 articles.

For the analysis, the abstracts of the selected papers were used. They may be expected to give a sufficient indication of what is the subject of the paper and thus provide an overview of the topics discussed in the respective fields [4]. In natural language processing, latent Dirichlet allocation (LDA) is a generative statistical model that allows sets of observations to be explained by unobserved groups that explain why some parts of the data are similar. LDA is an example of a topic model. The method for topic modelling employed in this paper, Latent Dirichlet Allocation (LDA), has greater flexibility using as input the whole abstracts of the papers. LDA is a generative probabilistic topic model proposed by [4], which can be used for the unsupervised identification of underlying topics in a large corpus of data without any prior knowledge of the topics[5,6]. Although the documents, or abstracts, are known and observed, the topics are hidden or latent [7]. The LDA was carried out in Python.

The selection criteria for our sample of studies were based on the following considerations: 1) The scientific articles indicate the preoccupations from the research field; 2) The scientific articles published in the main journals from the ISI Web of Science database offer a broad overview on the subject.

Research goals and questions

This work is based on the two goals with related motivations presented in Table 1.

G1: to investigate the relation between design patterns subject and software complexity by identifying the proportion between the articles written on the subject of design patterns and software complexity and test the correlation.

G2: to investigate if the two subjects are statistically different.

G2: to investigate the topics on design patterns from the software complexity subject.

Research questions were derived from each goal, and testable hypotheses formulated, as summarized in Table 1.

Table 1. Research goals and questions

\begin{tabular}{|l|l|l|l|}
\hline Goal & Research question & Motivation & Null Hypothesis H0 \\
\hline G1 & $\begin{array}{l}\text { Q1: Is there a directional relationship } \\
\text { between the topics on the subject of design } \\
\text { patterns and the topics on the subject of } \\
\text { software complexity? }\end{array}$ & $\begin{array}{l}\text { The subject of design } \\
\text { patterns and the subject } \\
\text { of software complexity } \\
\text { belong to the same field } \\
\text { of study, namely software } \\
\text { engineering }\end{array}$ & $\begin{array}{l}\text { No linear relationship } \\
\text { between the two subjects }\end{array}$ \\
\hline G2 & Q2: Are the two subjects of study different? & $\begin{array}{l}\text { While it has been } \\
\text { identified that design } \\
\text { patterns are important for } \\
\text { software complexity, the } \\
\text { topics on the subject vary } \\
\text { and treat different aspects }\end{array}$ & \begin{tabular}{l} 
The two subjects do not \\
\hline
\end{tabular} \\
\hline
\end{tabular}


The enunciated hypothesis that we established in our study were:

H1: there is a linear relationship between the subject of design patterns and the articles written on the subject of software complexity

H2: there is a difference in the topics treated by the articles belonging to these 2 subjects.

With respect to related work, our study intends to be a large attempt to evaluate the relationship between the subject of design pattern and software complexity. Also, it is the first work that examines the topics with techniques from natural language processing.

Additionally, we outlined the steps performed in the methodology: 1) identifying the articles written on the two subjects, identifying the topics in the field of design patterns by using LDA; 2) identifying the proportion of articles per each topic from design patterns and software complexity subject; 3) testing the hypotheses. Establishing whether there is a relationship between the two subjects has several applications in software engineering, including: A1) Predictions of topics on design pattern subject; A2) Predictions of topics on design pattern subject across software complexity subject.

\section{Results}

The proportion over Web of science categories for the papers from the design patterns subject is presented in Table 2 .

Table 2. The number of articles from the design patterns subject on science categories (Top Ten)

\begin{tabular}{|l|r|r|}
\hline Web of Science category & $\begin{array}{l}\text { Number of from Total } \\
\text { articles }\end{array}$ & $\begin{array}{l}\text { number of articles } \\
\text { (2045) }\end{array}$ \\
\hline Computer Science & 1068 & $52.22 \%$ \\
\hline Computer Science; Engineering & 147 & $7.19 \%$ \\
\hline Engineering & 62 & $3.03 \%$ \\
\hline Education \& Educational Research & 45 & $2.20 \%$ \\
\hline Computer Science; Telecommunications & 35 & $1.71 \%$ \\
\hline Computer Science; Engineering; Telecommunications & 24 & $1.17 \%$ \\
\hline Science \& Technology - Other Topics & 22 & $1.08 \%$ \\
\hline Engineering; Telecommunications & 21 & $1.03 \%$ \\
\hline $\begin{array}{l}\text { Computer Science; Engineering; Operations Research \& } \\
\text { Management Science }\end{array}$ & 19 & $0.93 \%$ \\
\hline Business \& Economics & 16 & \\
\hline
\end{tabular}

We chose to identify the topics starting from the Computer Science category because this category is well represented by a high number of articles. Though these lens we will discuss in the Results section the topics from the business category.

The software complexity subject is represented by a number of 302 articles. The distribution across different science categories is presented in Table 3. 
Table 3. The software complexity across science categories (Top Ten)

\begin{tabular}{|l|r|r|}
\hline Science category & $\begin{array}{l}\text { Number of } \\
\text { articles }\end{array}$ & $\begin{array}{l}\text { \%om Total } \\
\text { number of articles } \\
\text { (302) }\end{array}$ \\
\hline Computer Science & 146 & $48.34 \%$ \\
\hline Computer Science; Engineering & 42 & $13.91 \%$ \\
\hline Engineering & 19 & $6.29 \%$ \\
\hline Engineering; Telecommunications & 9 & $2.98 \%$ \\
\hline Mathematics & 6 & $1.99 \%$ \\
\hline Computer Science; Engineering; Telecommunications & 5 & $1.66 \%$ \\
\hline $\begin{array}{l}\text { Computer Science; Engineering; Operations Research \& } \\
\text { Management Science }\end{array}$ & 4 & $1.32 \%$ \\
\hline Computer Science; Operations Research \& Management Science & 4 & $1.32 \%$ \\
\hline Science \& Technology - Other Topics & 3 & $0.99 \%$ \\
\hline Automation \& Control Systems; Computer Science & 3 & $0.99 \%$ \\
\hline
\end{tabular}

The articles belonging to the Business Web of Science category address topics like: Semantic Enterprise Interoperability through Ontology Architectural Patterns, Variability patterns for business processes in BPMN, Modeling extended manufacturing processes with serviceoriented entities.

We applied LDA on the abstracts from the design patterns (computer science) articles. The resulted topics and their words and probability to appear in relation with each other is presented in Table 4.

Table 4. Topics on design patterns (computer science)- LDA

\begin{tabular}{|l|l|l|l|l|l|l|l|l|}
\hline Topic & \multicolumn{7}{|c|}{ Words/ Probability to appear in the same document } \\
\hline Model development & model' & 0.034 & applic' & 0.018 & system' & 0.018 & develop' & 0.014 \\
\hline System model & system' & 0.020 & applic' & 0.009 & model' & 0.008 & implement' $^{\prime}$ & 0.007 \\
\hline Analysis and program & program' & 0.017 & analysi' & 0.007 & method' & 0.007 & code' $^{\prime}$ & 0.006 \\
\hline Method implementation & method' & 0.013 & implement' & 0.012 & code' & 0.008 & develop' & 0.010 \\
\hline Software code & softwar' & 0.020 & code' & 0.012 & qualiti' & 0.01 & develop' & 0.010 \\
\hline Software language & softwar' & 0.020 & languag' & 0.017 & program' & 0.014 & develop' & 0.013 \\
\hline System software & system' & 0.029 & softwar' & 0.009 & implement' & 0.007 & architectur' & 0.006 \\
\hline Application development & system' & 0.019 & softwar' & 0.011 & develop' & 0.008 & applic' & 0.007 \\
\hline Program implementation & applic' & 0.014 & develop' & 0.013 & architectur' & 0.01 & implement' & 0.004 \\
\hline
\end{tabular}

We extracted the papers belonging to design patterns and software complexity on each topic. The results are presented in Table 5.

Table 5. The statistical results 
Proceedings of the IE 2019 International Conference

www.conferenceie.ase.ro

\begin{tabular}{|c|c|c|c|c|c|}
\hline Topic & $\begin{array}{l}\text { Articles written } \\
\text { on the subject } \\
\text { of design } \\
\text { patterns (Total) }\end{array}$ & $\begin{array}{l}\text { Articles written } \\
\text { on the subject } \\
\text { of software } \\
\text { complexity }\end{array}$ & $\begin{array}{l}\text { Design patterns } \\
\text { as proportion } \\
\text { from total } \\
\text { (1068 articles) }\end{array}$ & $\begin{array}{l}\text { Software } \\
\text { complexity as } \\
\text { proportion from } \\
\text { total (146 } \\
\text { articles) }\end{array}$ & $\begin{array}{l}\text { Software } \\
\text { complexity } \\
\text { versus design } \\
\text { patterns (as } \\
\text { ratio) }\end{array}$ \\
\hline $\begin{array}{l}\text { Model } \\
\text { development }\end{array}$ & 98 & 32 & $9.18 \%$ & $21.77 \%$ & 2.37 \\
\hline System model & 101 & 36 & $9.46 \%$ & $24.49 \%$ & 2.59 \\
\hline $\begin{array}{l}\text { Analysis and } \\
\text { program }\end{array}$ & 22 & 19 & $2.06 \%$ & $12.93 \%$ & 6.27 \\
\hline $\begin{array}{l}\text { Method } \\
\text { implementation }\end{array}$ & 31 & 6 & $2.90 \%$ & $4.08 \%$ & 1.41 \\
\hline Software code & 65 & 38 & $6.09 \%$ & $25.85 \%$ & 4.25 \\
\hline $\begin{array}{l}\text { Software } \\
\text { language }\end{array}$ & 51 & 17 & $4.78 \%$ & $11.56 \%$ & 2.42 \\
\hline System software & 128 & 69 & $11.99 \%$ & $46.94 \%$ & 3.92 \\
\hline $\begin{array}{l}\text { Application } \\
\text { development }\end{array}$ & 119 & 22 & $11.14 \%$ & $14.97 \%$ & 1.34 \\
\hline $\begin{array}{l}\text { Program } \\
\text { implementation }\end{array}$ & 49 & 7 & $4.59 \%$ & $4.76 \%$ & 1.04 \\
\hline
\end{tabular}

Pearson correlation $=0.72$ t-test $=0.005, \mathrm{p}$ value $=0.01$

The analyze revealed that there is an important number of articles written on the subject of software complexity that benefit from the well grounded subject of design patterns, but the numbers of articles on design patterns that benefit from software complexity is not that well represented. We found that between design patterns subject and software complexity subject there is a direct and strong relationship (Pearson correlation=0.72), so we reject the null hypothesis. The t-test value was 0.005 for a p value of 0.01 , so we were able to reject the null hypothesis. Therefore, there is a significant difference in the way the two subjects are treated by the authors of scientific articles from the mainstream research. We continued our analysis towards identifying the specific topics on design patterns from the software complexity subject. We eliminated the common keywords: design, system, complexity, software, application, model, program. Therefore, we were able to observe the topics that relate the two subjects.

Table 6. Topics from software complexity subject related to design patterns

\begin{tabular}{|l|l|}
\hline Topic & Method \\
\hline cohesion, estimation & clustering as pattern recognition method to assist in software refactoring \\
\hline quality requirements engineering & $\begin{array}{l}\text { knowledge management techniques and quality ontologies to support } \\
\text { Requirements Engineering (RE) activities }\end{array}$ \\
\hline software reusability & case based reasoning \\
\hline
\end{tabular}




\begin{tabular}{|l|l|}
\hline context IT, software maintenance & $\begin{array}{l}\text { the cognitive complexity metric as a measure of version to version } \\
\text { source code change. }\end{array}$ \\
\hline software change prediction & neural network based on software complexity measurements \\
\hline software reusability & WordNet (vocabulary) for case-based retrieval \\
\hline software maintenance & entropy semantically-based metric \\
\hline
\end{tabular}

In general, the articles written on the subject of software complexity address the main topic of "metric". LDA returned the word metric in each identified topic. Usually, these metrics are well established in theory and in practice. We noticed one single paper, entitled How changes affect software entropy: an empirical study [8], in which the authors analyzed how changes affect software entropy by: the presence of refactoring activities, the number of developers working on a source code file, the participation of classes in design patterns, and the different kinds of changes occurring on the system, classified in terms of their topics extracted from commit notes. The research subject of design patterns is represented by topics like pattern development and pattern usage.

\section{Conclusions}

In conclusion, in this study, the relations between software software complexity associated metrics and design patterns have been investigated. Also, this study emphasizes the importance of design patterns, the lack of standard metrics for design patterns, and the lack of standard ways for studying design patterns in relation with software complexity. The LDA technique proved its reliability in studying topics from the field of software complexity. The study revealed that, although software complexity and design patterns belong to the same subject area, namely software engineering, the topics vary.

\section{References}

[1] Henderson-Sellers, B., 1996. A book of object-oriented knowledge: an introduction to objectoriented software engineering. Prentice-Hall, Inc..

[2] Watson, A.H., Wallace, D.R. and McCabe, T.J., 1996. Structured testing: A testing methodology using the cyclomatic complexity metric (Vol. 500, No. 235). US Department of Commerce, Technology Administration, National Institute of Standards and Technology.

[3] Khomh, F. and Gueheneuce, Y.G., 2008, April. Do design patterns impact software quality positively?. In 2008 12th European Conference on Software Maintenance and Reengineering (pp. 274-278). IEEE.

[4] Blei, D.M., Griffiths, T.L. and Jordan, M.I., 2010. The nested chinese restaurant process and bayesian nonparametric inference of topic hierarchies. Journal of the ACM (JACM), 57(2), p.7.

[5] Guerreiro, J., Rita, P. and Trigueiros, D., 2016. A text mining-based review of cause-related marketing literature. Journal of Business Ethics, 139(1), pp.111-128.;

[6] Sugimoto, C.R., Li, D., Russell, T.G., Finlay, S.C. and Ding, Y., 2011. The shifting sands of disciplinary development: Analyzing North American Library and Information Science dissertations using latent Dirichlet allocation. Journal of the American Society for Information Science and Technology, 62(1), pp.185-204.

[7] Piepenbrink, A. and Nurmammadov, E., 2015. Topics in the literature of transition economies and emerging markets. Scientometrics, 102(3), pp.2107-2130.

[8] Canfora, G., Cerulo, L., Cimitile, M. and Di Penta, M., 2014. How changes affect software entropy: an empirical study. Empirical Software Engineering, 19(1), pp.1-38. 